\title{
O sofrimento nos períodos da grande indústria e do pós grande indústria
}

\author{
Lucas Mathias Ribeiro*
}

\begin{abstract}
Resumo
Trata dos aspectos do trabalho nos contextos de Grande Indústria e de PósGrande Indústria, em específico, discute-se as diferentes formas de sofrimento impostas ao trabalhador, que vão de males físicos, como exaustão, condições insalubres, e acidentes de trabalho, até problemas mentais, que variam de transtornos mentais menores a depressão e suicídio. São abordados os malefícios da questão da uberização, da terceirização, e outras formas de flexibilização do trabalho trazidas por novas tecnologias e métodos gerenciais, que aumentam a incerteza do trabalhador quanto ao futuro, enfraquecem a solidariedade, $\mathrm{e}$ colocam uma nova aparência que mascara as relações de classe por meio de termos como "empreendedor de si". As incertezas e a falta de solidariedade que são colocadas contribuem para o aumento das doenças mentais relacionadas ao trabalho, um problema invisibilizado que aflige boa parte dos trabalhadores intelectualizados no mundo do trabalho da pós grande indústria. Palavras-chaves: trabalho, depressão, suicídio, uberização, superexploração do trabalho.
\end{abstract}

\begin{abstract}
Deals with work aspects in the context of Large Scale Industry and the Post-Large Scale Industry, specially the different forms of suffering imposed to the workers, ranging from physical ailments such as exhaustion, unhealthy conditions, and work-related accidents, to mental problems ranging from minor mental disorders to depression and suicide. An approach is taken on the harms of the issue of uberization, outsourcing, and other forms of labor flexibility brought about by new technologies and managerial methods, which increase the worker's uncertainty about the future, weaken solidarity, and put on a new appearance that masks relationships of class by means of terms like "self-entrepreneur". The uncertainties and the lack of solidarity that are put together contribute to the increase in mental illnesses related to work, an invisible problem that afflicts many of the intellectualized workers in the post-large scale industrial world. Keywords:work, depression, suicide, uberization, overexploitation of work.
\end{abstract}

*Bacharelando em Ciências e Humanidades na UFABC - contato: lucasmathias22@hotmail.com 


\section{Introdução}

A superexploração do trabalho ${ }^{1}$ e as condições precárias para sua realização são problemas que se observam no modo de produção capitalista e que têm causado sofrimento desde o seu surgimento. Diversos exemplos foram dados por Karl Marx em sua obra, O Capital, a respeito dos abusos desmedidos cometidos pela classe burguesa contra o proletário em meados do século XIX: crianças que possuíam jornadas de trabalho de 15 horas já aos 7 anos, taxas alarmantes de óbitos ocasionados por doenças pulmonares que acometiam os oleiros, empregados da manufatura de palitos de fósforo (muitos deles com menos de dez anos de idade) sendo acometidos por tétano, entre outros exemplos de notável morbidez. Além disso, havia também a adulteração de alimentos como o pão, que possuía "certa quantidade de suor humano, misturada com supurações de abscessos, teias de aranha, baratas mortas, e fermento podre alemão, além de alume, arenito e outros agradáveis ingredientes minerais" (MARX, 2017, p. 323).

Tais condições são colocadas pela classe burguesa a fim de expandir o máximo possível o trabalho excedente. A jornada de trabalho é estendida ao máximo, gerando mais-valia absoluta, enquanto que o barateamento da produção de alimentos e a precarização da vida geram a desvalorização real da força de trabalho e uma consequente mais-valia relativa ${ }^{2}$.

Muita coisa mudou na vida da população trabalhadora desde a revolução industrial, e da passagem dos períodos de grande indústria para o pós grande indústria, Marx dá o exemplo da conquista por parte dos trabalhadores de uma jornada normal de trabalho, fixada por lei; há o advento da democracia representativa; a conquista de um salário mínimo, e outros direitos trabalhistas existentes hoje. Mas se engana quem pensa que os ganhos políticos, o progresso técnico, e o avanço das tecnologias de informação e comunicação vieram para superar os períodos de sofrimento. Embora Guy Standing (2011) conjecture a respeito da emergência do "precariado" como nova classe, parece que a desorganização e a vulnerabilidade são elementos presentes na vida da classe trabalhadora desde o nascimento do capitalismo.

Em seu ensaio "Sobre as possibilidades econômicas de nossos netos", de 1931, John Maynard Keynes especula sobre os impactos que o progresso tecnológico traria nos próximos cem anos, e prevê a inauguração de uma nova era para a Inglaterra na qual o problema econômico, isto é, a questão da subsistência, estará resolvido, podendo então o homem se ocupar do lazer. $\mathrm{O}$ autor meramente cita o fato de que alguns países irão sofrer por "não estarem na vanguarda do progresso", o desemprego tecnológico e ganância se resolveriam por meio de fortes suposições que fogem do escopo deste ensaio. Além disso, ele repudia "o pessimismo dos revolucionários, que acham que as coisas são tão ruins que nada pode nos salvar exceto uma mudança violenta".

1 MARINI (1973) identifica três mecanismos que determinam a superexploração do trabalho: a intensificação do trabalho, a prolongação da jornada de trabalho e a expropriação de parte do trabalho necessário para que o trabalhador reponha sua força de trabalho (ou seja, a redução do consumo). Por meio de tais mecanismos é imposto ao trabalhador um dispêndio de força de trabalho acima do normal, junto de uma retirada do consumo que lhe é indispensável para manutenção de sua força, o que significa que o trabalho é remunerado abaixo de seu valor, o que corresponde à superexploração.

2 O mecanismo pelo qual se dá esta geração de mais-valia é descrito nas seções III, IV e V de Marx (2017) 
Na década de 1980 ganhou força no universo acadêmico essa ideia de um capitalismo automatizado, que não necessitasse de trabalho humano para a produção das mercadorias. As mais diversas mudanças de aparências vividas no capitalismo levaram Keynes e os demais acadêmicos a imaginarem um futuro de superação do "problema econômico". Observa-se, no entanto, que nesses países centrais onde a massa trabalhadora conquistou direitos, a maneira de explorar a força de trabalho se adequou às novas exigências, e o antigo método de superexploração da mão de obra foi exportado para o terceiro mundo.

O presente artigo tem como objetivo fazer, dentro de seu limitado espaço, uma discussão tanto a respeito destas novas formas de exploração no mundo do trabalho pós industrial, quanto a respeito o sofrimento daqueles que se encontram fora da assim chamada "vanguarda do progresso". Para isso haverá uma primeira sessão na qual se falará a respeito de exemplos de sofrimentos mais contemporâneos causados pela superexploração na grande indústria, mostrando que, embora o foco aqui seja as novas formas de sofrimento, os males da grande indústria continuam atuais e não devem ser negligenciados, esta sessão será seguida de outra que compreenderá o foco deste trabalho, que é o sofrimento do trabalho dito "intelectualizado", presente no pós grande indústria. Por último, haverá as Considerações Finais a respeito do tema.

\section{Mazelas do trabalho na grande indústria}

Para Marx (2017, cap.13), no período de grande indústria ocorre uma revolução do modo de produção que se dá através da transformação da ferramenta em máquina, essa transformação ocorre quando a ferramenta é transferida do homem para um mecanismo, este mecanismo, a máquina, se apropria do trabalho do homem, que passa a servir apenas como mera força motriz, e como vigia do trabalho da máquina (mudança definidora da Revolução Industrial). Estas novas máquinas se tornam meio de utilizar trabalhadores com menos força muscular, podendo transformar em trabalhadores todos os membros de uma família, essa absorção de toda a família desvaloriza o valor do trabalho, pois reparte entre seus membros um valor que antes deveria ser necessário para manutenção de toda uma família, e passa a ser o suficiente apenas para a manutenção de si.

Estas novas formas de produção colocadas pela Revolução Industrial foram sendo impostas, em diferentes datas, nos mais diversos países, por meio da divisão internacional do trabalho, e foram levando consigo a superexploração do trabalhador. Essa superexploração se dá por conta da necessidade crescente da burguesia de aumentar a massa de valor produzida no intuito de compensar a tendencial queda na taxa de lucro, e é mais frequentemente observada no terceiro mundo, cuja economia é primariamente exportadora e, portanto, vê a realização de sua produção ser efetuada no mercado externo. Estando separadas as esferas da circulação e da produção, a realização do produto passa a se dar independentemente do consumo individual dos trabalhadores nacionais, o que resulta, segundo Marini (1973, p. 14), em uma tendência de "explorar ao máximo a força de trabalho do operário, sem se preocupar em criar as condições para que este a reponha". Ainda segundo Marini (1973, p. 4), a grande indústria moderna teria sua criação obstaculizada sem o papel desempenhado pelos países dependentes como fornecedores de matéria prima e produtos agrícolas, pois isto permite a especialização das sociedades centrais na atividade industrial e a redução do valor real da força de trabalho, permitindo que o aumento de produtividade 
se tornasse taxas mais altas de mais-valia.

O desenvolvimento das relações de trabalho desde a Revolução Industrial tem sido ambíguo, de um lado os trabalhadores têm conquistado direitos, sobretudo nos países centrais do sistema capitalista, de outro a classe burguesa tem encontrado novas formas de realizar a superexploração do trabalho, por meio de novos métodos gerenciais e técnicos, ainda podendo se observar casos muito semelhantes aos descritos por Marx (2017, p.323). Ricardo Antunes (2018) dá exemplos disso: indústrias de tecidos com jornadas de doze horas em locais de trabalho degradantes na Índia; o trabalho feminino marcado pela opressão, demissões, condições sub-humanas e assédio na Coreia do Sul; o trabalho dos funcionários da Samsung sendo marcado pelos adoecimentos e contaminações; Minas de carvão chinesas onde o trabalho se dá sob altas temperaturas; além do modo de funcionamento do capitalismo das transnacionais neste país, que recebe empresas de terceirização de montagem de produtos eletrônicos. Só na Foxconn (empresa de terceirização de montagem que atende Apple, Nokia, entre outros) 17 jovens trabalhadores tentaram suicídio nos primeiros oito meses de 2010, tendo 13 conseguido (NGAI, CHAN, SELDEN, 2013), a produção de eletrônicos empregava nesse período 1,4 milhão de pessoas (ANTUNES, 2018), que trabalhavam mais de dez horas diárias por salários irrisórios.

Durante o período da Ditadura Militar a precariedade das condições de trabalho se acentuou no Brasil com a opressão de organizações de trabalhadores. Vendo os direitos trabalhistas como obstáculos ao progresso, o governo golpista acabou com o sistema de estabilidade do trabalho, o que gerou forte pressão salarial para baixo (por conta de passar a haver a possibilidade de demissões em massa), a perda do poder de compra fez com que, em 1974, o trabalhador tivesse que trabalhar mais que o dobro do tempo que era necessário, em 1959, para comprar a mesma quantidade básica de alimentos (DIEESE, 1979 apud ALVES, 2005); as idas ao banheiro eram controladas e a produtividade tinha de aumentar sempre, sem que isto tivesse alguma contrapartida de aumento dos salários. Segundo Silva (2015, p. 156):

De modo geral, a elevação da produtividade física do trabalhador brasileiro durante a ditadura militar não foi resultante apenas de investimentos em tecnologia mais avançada, mas, sobretudo, das mudanças nas relações de trabalho impostas pela coerção política, instabilidade, arrocho salarial, carestia e rotatividade da força de trabalho.

A terceirização no Brasil também é um elemento que tem levado à precarização e à intensificação da jornada de trabalho, associando-se a novas tecnologias e métodos gerenciais que buscam uma aceleração intensa da atividade laborativa, gerando sobrecarga de informações sobre o trabalhador; intensificação das atividades, pressão sobre o tempo e o ritmo de trabalho, altas exigências de mobilidade e flexibilidade, além da insegurança de manutenção do emprego, elementos que, segundo a Organização Internacional do Trabalho (2012), são os principais causadores de estresse no ambiente de trabalho.

Toda essa pressão se torna possível porque a terceirização divide os trabalhadores, tornando mais difícil a sua organização sindical, desmantelando a resistência contra tais abusos (ANTUNES, 2011), o que levou ao aumento da prevalência de doenças relacionadas ao trabalho, como as Lesões por Esforços Repetitivos (LER), também denominadas como Distúrbios Osteomusculares Relacionados ao Trabalho (DORT). 
Segundo Alex Gomes, representante da comissão interna de prevenção de acidentes (Cipa), na fábrica da GM de São José dos Campos:

\begin{abstract}
Esse aumento dessa pressão interna na fábrica, o trabalhador com medo de ser mandado embora, ele trabalha o tempo todo com esse pavor na cabeça, que é um clima de terror. A gente vive um clima constante de terror. Depois de 2011 só se agravou. O cara entra todo dia na fábrica achando que vai ser demitido. Isso tira a atenção dele na hora de fazer o trabalho, aumenta a incidência, isso gera um risco maior de acidente. (PRAUN, 2014, p. 72)
\end{abstract}

No campo, as relações de trabalho são marcadas por estarem à margem da lei, contando com contratação de mão de obra temporária, emprego de crianças e adolescentes, chegando ao caso de uso de mão de obra escrava (MINISTÉRIO DA SAÚDE DO BRASIL, 2001, p. 19). Além disso, em muitos setores a remuneração está atrelada à produção realizada, o que leva o trabalhador a exaurir suas energias buscando condições para a sobrevivência da própria família. Isto aumenta o lucro, o mais-valor, e também os acidentes, mutilações, e mortes no trabalho, tendo como caso emblemático o setor sucroalcooleiro no Brasil (ANTUNES, 2018).

Os ganhos de produtividade causados pelas novas formas gerenciais já citadas geram inúmeros trabalhadores excluídos do processo produtivo e desvalorização, um desemprego estrutural que barateia a mão de obra destes excluídos e que faz surgir o chamado "novo proletariado de serviços", que contrasta com o tradicional proletariado de serviços (médicos e advogados) pela sua baixa qualificação: são os trabalhadores e trabalhadoras de callcenters, telemarketings, supermercados, empresas de fastfood etc.

Naturalmente, à medida que suas populações se especializam e a produção é mandada para outros países, a mão de obra desqualificada nacional se desvaloriza (o exército de reserva agora se apresenta como algo global), sendo assim, o Primeiro Mundo não fica de fora das observações a respeito da superexploração do trabalhador: a norte-americana Walmart remunera seus trabalhadores nos patamares mais baixos, explorando as populações já estigmatizadas no mundo do trabalho: mulheres, jovens, negros, e deficientes, com o objetivo de pagar salários reduzidos. Na França são dados exemplos da construção civil e da mineração, áreas de atuação perigosas e violentas. "Acidentes, contaminação, devastação do corpo produtivo, mortes, tudo isso ocorre na sociedade dos que imaginaram que as tecnologias da informação eliminariam o trabalho mutilador"(ANTUNES ${ }^{3}, 2018$, p. 20).

\title{
2 Mazelas do trabalho no pós grande indústria
}

A reestruturação do capital produtivo, iniciada na década de 70 por conta das novas tecnologias de informação e comunicação que foram desenvolvidas, por um lado acentuou a informalização do trabalho, expulsando do processo produtivo inúmeros trabalhadores, e possibilitando a posterior precarização; por outro lado, trouxe o "benefício"da intelectualização do trabalho (entre aspas pois é algo bastante questionável, já que, como se verá adiante, levou consequências psicossomáticas bastante negativas ao trabalhador).

3 ANTUNES (2018, p. 20). vale ressaltar que o autor cita, no capítulo 1, documentários como Behemoth, de Zhao Liang; Consumed, de Richard Seymour; Machines, de Rahul Jain; Brumaire, de Joseph Gordillo; Factory Complex, de Im Heung-soon; What We Have Made, de Fanny Tondre; que tratam a respeito destas questões de superexploração nos diversos países 
Com a crise estrutural que o capitalismo vivenciou em 2008, o processo de precarização do trabalho, iniciado na década de 70 , passou por uma significativa expansão no mundo todo (ANTUNES, 2018 p. 55), o que resultou em uma explosão de revoltas sociais. Na Grécia ocorreu, na virada da década, diversas manifestações contra o receituário do Fundo Monetário Internacional e do Banco Central Europeu; em Portugal, manifestantes jovens e desempregados foram às ruas em 2011; o mesmo ocorreu com a juventude Espanhola, com a geração Ni-Ni, ni estudia, ni trabaja; nos Estados Unidos, há o movimento Occupy Wall Street, um movimento de protesto contra a desigualdade socioeconômica, a ganância, a corrupção e a indevida influência das empresas - sobretudo do setor financeiro - nos rumos da sociedade.

Nos casos em que a superexploração não pode ser feita assim de maneira tão evidente quanto na grande indústria, ela se adéqua utilizando estas novas tecnologias. A nova forma de contratação sem determinação de horas, por exemplo, na qual os trabalhadores podem ser convocados a qualquer momento, devendo estar sempre disponíveis, e recebendo apenas pelo trabalho realizado, passa a englobar médicos, enfermeiros e advogados; o uso de Hackatons e outros concursos semelhantes são também exemplos de exploração do trabalho que remuneram apenas pelo resultado gerado, tudo isso atinge profissões já mais qualificadas. Essa flexibilização do mercado de trabalho proporcionada pelas tecnologias de comunicação e informação gera, praticamente, uma forma de escravidão digital na qual há uma ampliação do trabalho morto, com a "internet das coisas" dominando o trabalho, o que chegou a ser definido pelo seu caso emblemático: uberização, e se disfarça em termos como "empreendedor" ou "burguês-de-si-mesmo" (ANTUNES, 2018 p. 34-37).

Sendo assim, a intelectualização do trabalho logo foi seguida de novas formas de geração de trabalho excedente (ANTUNES, 2018), a subsunção do trabalho ao mundo maquínico continua, sendo que a máquina-ferramenta foi apenas substituída pela máquina informacional-digital, e o sobretrabalho se dá em contextos de informalidade, terceirização, "corporativismo", "empreendedorismo", regimes de trabalho intermitente, e outros, gerando um universo de trabalho invisibilizado, uberizado, no qual a remuneração é incerta e os trabalhadores que se tornam sobressalentes continuam formando bolsões de excluídos que aumentam o medo do desemprego e permitem maior retração salarial dos que estão empregados, além de viabilizar um discurso que prega o desmonte da legislação social protetora do trabalho.

Este trabalho intelectualizado gera uma processualidade de criação de máquinas cada vez mais "inteligentes", passando a executar atividades que antes eram executáveis apenas pelo esforço humano, levando a enganos como o de Habermas de interpretar o trabalho vivo como algo cada vez mais residual na geração de valor. Essas novas modalidades de trabalho imaterial são, na verdade, expressões de trabalho vivo que participam do processo de geração de valor.

O trabalho é, segundo Marx (2004), uma exteriorização, pois o trabalhador não é dono do fruto do próprio trabalho, sendo assim, ele não vê no trabalho uma atividade vital e sim um meio para satisfação de carências, sendo assim, o trabalhador se vê livre apenas em suas funções animais, a alienação inerente ao modo de produção capitalista faz com que os indivíduos não se sintam conectados com a sua atividade laboral. Se na grande indústria o esforço físico do trabalhador lhe é estranhado e explorado ao ponto de causar lesões e deformações, no pós grande indústria o capital se apropria de seu intelecto, a alienação e o estranhamento impregnam o subjetivo do trabalhador, e como consequência as doenças torturarão não seu corpo, mas sua mente. 
Em História e Consciência de Classe, no ensaio "A coisificação e a consciência do proletariado", Lukács demonstrou como a fragmentação taylorista do trabalho penetrava até a "alma do trabalhador", alicerçando os fundamentos da coisificação, numa complexa articulação entre materialidade e subjetividade operária. Gramsci, em seu ensaio "Americanismo e fordismo", explorou a ideia do homem integral para o capital, em que até o controle da sexualidade era concebido, de modo a canalizar a virilidade masculina na produção maquínica. (ANTUNES, 2018, p. 102)

As doenças mentais ocupacionais têm ainda muito pouca visibilidade, ainda que sejam responsáveis pela morte de seis vezes mais pessoas do que os acidentes de trabalho (OIT, 2013, p. 4). Elas surgem de maneira sutil, afetam não só o bem estar do próprio indivíduo, mas também as suas relações sociais e familiares. Conforme dados da Organização Mundial da Saúde (OMS), 30\% dos trabalhadores ocupados possuem Transtornos Mentais Menores ${ }^{4}$.

Muitos, no entanto, possuem problemas ainda mais graves, chegando a casos de depressão. A origem desse adoecimento está, sem dúvida, ligada a aspectos laborais, em especial à individualização do trabalho, que rompe com a solidariedade existente entre os trabalhadores ${ }^{5}$, criando competições que, junto da alienação, levam a um adoecimento psíquico, de maneira que essa ligação entre o trabalho e a ideação suicida chega à sua prova mais contundente: o suicídio no local de trabalho. (DEJOUR, BËGUE, $2010)^{6}$

O desmonte das condições para a solidariedade entre os trabalhadores têm contribuído para o aumento da incidência de suicídio nos locais de trabalho, estando ligado aos sentimentos de isolamento e solidão. Esta perda da solidariedade começa a se observar, conforme Dejours e Bègue (2010), na década de 1980, antes da qual a incidência de tais suicídios era muito menor. Em uma pesquisa a respeito desses casos na França nos anos 2000, os autores citados afirmam que o suicídio é uma mensagem destinada à comunidade da qual o sujeito fazia parte.

Que um suicídio possa ocorrer no local de trabalho indica que todas essas condutas de ajuda mútua e solidariedade - que não eram nem mais nem menos que uma simples prevenção das descompensações, assumidas pelo coletivo de trabalho - foram banidas dos costumes e da rotina da vida de trabalho. Em seu lugar instalouse a nova fórmula do cada um por si, e a solidão de todos tornou-se

4 Transtornos mentais menores (TMM) representam quadros menos graves e mais frequentes de transtornos mentais. Os sintomas incluem alterações de memória, dificuldade de concentração e de tomada de decisões, insônia, irritabilidade e fadiga, assim como queixas somáticas (cefaleia, falta de apetite, tremores, sintomas gastrointestinais, entre outros) (FIOROTTI et al., 2010)

5 "Ver, entre outros, os estudos desenvolvidos por Danièle Linhart, A desmedida do capital, cit.; Christophe Dejours, "A avaliação do trabalho submetida à prova do real", em Laerte Idal Sznelwar e Fausto Leopoldo Mascia (orgs.), Cadernos TTO (São Paulo, Blucher, 2008); Christophe Dejours e Florence Bègue, Suicídio e trabalho: o que fazer? (Brasília, Paralelo 15, 2010); Vincent de Gaulejac, Gestão como doença social: ideologia, poder gerencialista e fragmentação social (Aparecida, Ideias e Letras, 2007); Edith Seligmann-Silva, "Psicopatologia no trabalho: aspectos contemporâneos", Anais do Congresso Internacional sobre Saúde Mental no Trabalho, Goiânia, CIR, 2007, e Trabalho e desgaste mental: o direito de ser dono de si mesmo (São Paulo, Cortez, 2011).", nota de Antunes (2018)

6 Segundo Durkheim (2011, p. 165), "existe para cada grupo social uma tendência específica ao suicídio que não é explicada nem pela constituição orgânico-psíquica dos indivíduos nem pela natureza do meio físico", ou seja, é uma intenção de acabar com a própria vida que é oriunda de aspectos da própria sociabilidade do grupo, sendo assim, pode-se interpretar que a massa trabalhadora possui aspectos sociais próprios que influenciem na sua opção pelo suicídio, em especial o que se dá no local de trabalho. 
regra. Agora, um colega afoga-se e não se lhe estende mais a mão. Em outros termos, um único suicídio no local de trabalho - ou manifestamente em relação ao trabalho - revela a desestruturação profunda da ajuda mútua e da solidariedade. (DEJOURS, BÈGUE, 2010, p. 21)

O sofrimento no ambiente de trabalho dá de tal forma que causa constrangimento a todos, os que sofrem diretamente com ele dissimulam seus sentimentos, seja pela vergonha da própria condição, seja pelo medo de se tornar motivo de chacota. Quando enfim o indivíduo chega ao ponto de tirar a própria vida no local de trabalho, nada muda na rotina dos demais, a ação da polícia e alguma faxina que se torne necessária não vem seguida de uma reação coletiva, impera uma espiral de silêncio e sofrimento que agrava o sentimento de impotência de todos.

Além disso, o universo laboral contemporâneo gera uma exclusão social materializada no desemprego, como bem lembrado por Rocha e Bussinguer (2016): "a exclusão de indivíduos do mercado de trabalho pode levá-los não só à privação material, mas também à restrição de direitos, de segurança socioeconômica e de autoestima". Dessa forma, a organização do trabalho imposta pelo sistema capitalista coloca a todos aqueles que não possuem nada além da própria força de trabalho em constante ameaça de sofrimento, seja no emprego, seja no desemprego.

\section{Considerações finais}

O mundo do trabalho no modo de produção capitalista é marcado pela alienação em todas as suas formas, seja a da grande indústria, seja no trabalho "intelectualizado" do pós-grande indústria, esta alienação, somada à superexploração do trabalho e às flexibilizações do trabalho têm causado sofrimentos que vão desde a deformação e mutilação do corpo do trabalhador, até transtornos mentais que se interiorizam continuamente com o passar do tempo.

Indo ao encontro do que aqui foi dito, cabe ressaltar a interpretação de um importante economista estadunidense, Thorstein Veblen, segundo o qual não seria absurdo pensar que a natureza teria selecionado, em períodos mais remotos, aqueles humanos que fossem dotados de um ímpeto ao trabalho pois, neste período, produção seria igual a sobrevivência. A rejeição ao trabalho só poderia aparecer posteriormente, quando as condições materiais de existência já tivessem superado o nível das necessidades básicas. "O sentido de que o trabalho é algo ruim, fonte de desutilidade como queriam os neoclássicos, em Veblen, resultaria de uma convenção social, não sendo uma propriedade inata do homem" (CAVALIERI, 2009), isto porque o trabalho no modo de produção capitalista não parece ser um esforço útil (algo que claramente pode ser associado à alienação em Marx).

Faz-se necessário, portanto, uma nova concepção de nossas formas de lidar com o trabalho que não seja ligada ao benefício de um único indivíduo ou grupo, passando por cima da vida de milhões. Alternativas a isso não faltam, são apresentadas por teóricos marxistas, institucionalistas, estão presentes em discussões a respeito de economia solidária e cooperativismo, literaturas que não reproduzem os mitos perpetuadores da predação que estratos superiores da sociedade impõe sobre a população subjacente e que distorcem nossa racionalidade (DUGGER, 1987, 1988). 


\begin{abstract}
Nas sociedades capitalistas avançadas [a proeza] toma a forma da repetição ad nauseam das histórias de sucesso desse ou daquele empreendedor individual, acompanhadas de uma coleção de material literário de baixa qualidade, calcada no biografismo chão e na metafísica corporativa vendida sob o rótulo de desenvolvimento pessoal, coaching ou algum termo análogo inventado semestralmente por algum apologeta da subserviência do trabalho ao capital. (SIMIQUELI, 2016, p. 60-61)
\end{abstract}

Por fim, tendo em vista as condições do povo trabalhador expostas no presente trabalho, cabe refletir a respeito do repúdio de Keynes ao pessimismo dos revolucionários. Com o capitalismo tendo passado por suas mais diversas etapas sem criar novas estruturas produtoras de patologias sociais, haveria no fim das contas uma salvação que não passasse por uma mudança violenta?

\title{
Referências bibliográficas
}

ALVES, M. H. M. Estado e Oposição no Brasil (1964/1984). Bauru: Edusc, 2005.

ANTUNES, R. Sindicalismo de classe versus sindicalismo negociador de Estado. Instituto Humanitas Unisinos. 2011.

ANTUNES, R. O Privilégio da Servidão: o novo proletariado de serviços na era digital. 1. ed. - São Paulo: Boitempo, 2018.

CAVALIERI, M. A. R. O Surgimento do Institucionalismo Norte-Americano: Um Ensaio Sobre o Pensamento e o Tempo de Thorstein Veblen. Tese (Doutorado em Economia) Universidade Federal de Minas Gerais. Belo Horizonte: Cedeplar, 2009.

DEJOURS, C.; BÈGUE, F. Suicídio e trabalho: o que fazer?. Brasília: Paralelo 15, 2010.

DIAS, E. C. (org.) Doenças relacionadas ao trabalho: manual de procedimentos para os serviços de saúde. Brasília: Ministério da Saúde do Brasil, 2001.

DUGGER, W. Corporate Hegemony and Market Mythology. Challenge, v. 29, n. 6, p. 55-58, 1987.

DUGGER, W. Radical Institutionalism: Basic Concepts. Review of Radical Political Economics 1988.

DURKHEIM, É. O suicídio: estudo de sociologia. São Paulo: Wmf Martins Fontes, 2011.

FIOROTTI, K.P.; ROSSONI, R.R.; BORGES, L.H.; MIRANDA, A.E. Transtornos mentais comuns entre os estudantes do curso de medicina: prevalência e fatores associados. $J$ Bras Psiquiatr. v. 59, n. 1, p. 17-23, 2010.

MARINI, M. Dialética da Dependência. Editora Expressão Popular, 2005

MARX, K. Manuscritos econômico-filosóficos. São Paulo, Boitempo, 2004

MARX, K. O Capital: crítica da economia política: livro I: o processo de produção do capital. São Paulo: Boitempo, 2017

ORGANIZAÇÃO INTERNACIONAL DO TRABALHO. A prevenção das doenças profissionais. Genebra: OIT, 2013. Disponível em: <https://www.ilo.org/wcmsp5/groups/ public/---ed_protect/---protrav/---safework/documents/publication/wcms_221920. pdf $>$. Acesso em: 10 de Abril de 2019 
ORGANIZAÇÃO INTERNACIONAL DO TRABALHO. Why stress at work matters. Disponível em: <http://www.ilo.org/global/about-the-ilo/newsroom/comment-analysis/ WCMS_184786/lang \T1 \textemdashen/index.htm>. Acesso em: 05 de Maio de 2019

PRAUN. L. Não sois máquina! Reestruturação produtiva e adoecimento na General Motors do Brasil. Tese (doutorado em Sociologia) - Instituto de Filosofia e Ciências Humanas, Unicamp, Campinas, 2014

NGAI, P.; CHAN, J.; SELDEN, M. The politics of global production: Apple, Foxconn and China's new working class. New Technology, Work and Employment, v. 28, n. 2, p. 100-115, 2013.

ROCHA, S. H.; BUSSINGUER, E. C. A. A invisibilidade das doenças mentais ocupacionais no mundo contemporâneo do trabalho. Pensar, v. 21, n. 3, p. 1104-1122, 2016.

STANDING, G. The Precariat: the new dangerous class. Nova York, Bloomsburry, 2011

SILVA, A. B. R. B. Brasil, o "campeão mundial de acidentes de trabalho": controle social, exploração e prevencionismo durante a ditadura empresarial-militar brasileira. Dossiê - Trabalho, saúde e medicina na América Latina. Mundos do Trabalho, v. 7, n. 13, 2015. 